УДК 94(47).073 - 94(47).081

\title{
ВОЗВРАЩАЯ ИМЕНА ГЕРОЕВ ЗАБЫТОЙ ЭПОХИ (О ПОЛНЫХ ГЕОРГИЕВСКИХ КАВАЛЕРАХ ЛИНЕЙНОГО КАЗАЧЕСТВА КУБАНИ ЭПОХИ КАВКАЗСКОЙ ВОЙНЫ)
}

В статье рассматривается сюжет о полных георгиевских кавалерах из линейных полков Кубани эпохи Кавказской войны, который остается по-прежнему в разряде малоизученных проблем. Имперская историография Кубани не обращала должного внимания на статус нижних чинов, награждавшихся знаком отличия военного ордена Св. Георгия, и поэтому сведения, публиковавшиеся даже спустя несколько лет после окончания Кавказской войны, оказываются несвободными от ошибок. Безвестный автор заметки, помещенной в региональной газете в 1869 г. к числу здравствовавших в тот момент полных георгиевских кавалеров отнес отставного казака Ивана Чернышева из 1-й (Кавказской) бригады и отставного урядника Мартына Братухина из 2-й (Кубанской) бригады Кубанского войска. Привлечение документов из различных центральных и региональных архивов позволило выявить допущенную ошибку и, помимо урядника Братухина, установить другого действительного обладателя полного Георгиевского банта.
Таковым героем оказался сотник Иван Сесекин, происходивший, как и Братухин, из ст. Прочноокопской. Жители данного казачьего поселения отличались массовой приверженностью к старообрядчеству, что создает трудности в реконструкции казачьих биографий. Вместе с тем, казаки-старообрядцы весьма заметно проявили себя в многолетней войне с горцами, и именно ст. Прочноокопская дала в описываемую эпоху более сотни георгиевских кавалеров и около трех десятков офицеров в Кавказское линейное, позднее - в Кубанское казачье войско. Тема, посвященная георгиевским кавалерам линейных полков Кубани эпохи Кавказской войны, все еще до конца не раскрыта, что требует дополнительных исследовательских усилий.

Ключевые слова: георгиевские кавалеры, линейные полки Кубани, эпоха Кавказской войны, старообрядческая община, Кавказская и Кубанская бригады, Кавказское линейное войско, Кубанское казачье войско, станица Прочноокопская, горцы.

\section{RETURNING THE NAMES OF THE HEROES OF THE FORGOTTEN EPOCH} (ON COMPLETE ST. GEORGE CAVALIERS OF THE LINE COSSACKS OF THE KUBAN DURING THE CAUCASIAN WAR)

The article discusses the plot devoted to the complete St. George cavaliers from the line Cossack's regiments of the Kuban in Caucasian War period. This problem still remains in the category of little-studied. The imperial historiography of the Kuban did not pay due attention to the ordinary Cossacks, who were awarded the military order of St. George for their many years struggle against the highlanders. In practice, it turns out that there were no systematic accounting of heroes and relevant statistics for Cossack's regiments and villages. The unknown author of a note published in a regional newspaper in 1869 included the retired Cossack Ivan Chernyshev from the 1-st (Caucasian) brigade and the retired Cossack's sergeant Martyn Bratukhin from the 2-nd (Kuban) brigade of the Kuban Cossack's army among the complete cavaliers who were still alive at that time. According to various documents found in central and regional archives, it turned out that the Cossack Ivan Chernyshev was nott the complete cavalier. In spite of the found mistake it could be possible to identify another hero of the passed epoch. Such holder of a prestige award was a Cossack's officer (sotnik) Ivan Sesekin. It is interesting to stress that both heroes originated from stanitsa Prochnookopskaya. This Cossack's village was well-known as a greatest centre of Old Believers who conflicted with Orthodox clergy. At the same time, Cossacks-Old Believers showed themselves very noticeably in a long-term war with the highlanders. About more than a hundred St. George cavaliers and about three dozen Cossack's officers originated from stanitsa Prochnookopskaya and they glorified many times the Caucasian Line, and later the Kuban Cossack Army. The theme devoted to the St. George cavaliers of the Cossack's regiments of the Kuban in Caucasian War period still requires additional research efforts.

Key words: St. George cavaliers, line regiments of the Kuban, the epoch of the Caucasian war, the Old Believer community, the Caucasian and Kuban brigades, the Caucasian line Cossack's army, the Kuban Cossack's army, the Cossack's village (stanitsa Prochnookopskaya), highlanders.

\footnotetext{
1 Автор выражает самую искреннюю признательность за помощь в подготовке данной статьи: Е. Н. Герасименко (г. Москва), А. И. Сапожникову (г. Санкт-Петербург) и А. Ю. Соколову (ст. Новотитаровская Краснодарского края).
} 
Пробуждение интереса к военной истории Российской империи, имевшее место за последние годы, принесло весьма внушительные результаты. В преддверии 100-летнего юбилея начала Первой мировой войны, основательно забытой в советский период, был, например, осуществлен мегапроект С. Б. Патрикеева (14 томов, каждый объемом около и свыше тысячи страниц), увековечивший память о более чем 900 тысячах нижних чинах Русской армии, представленных к Георгиевским крестам и медалям [32]. Впечатляет и литература, непосредственно посвященная георгиевским кавалерам Кубанского казачьего войска - участникам Великой войны [34], особенно - капитальный труд столичного историка П. Н. Стрелянова (Калабухова), увидевший свет в конце 2017 г. [35]. Вместе с тем, говоря о героях кавказского пограничья, нельзя не отметить, что вклад кубанцев (а ранее - линейцев и черноморцев) в кампании Российской империи еще до конца не изучен, предстоит достаточно кропотливая работа по установлению тех, кто на протяжении $\mathrm{XIX}$ столетия награждался знаком отличия военного ордена Святого Георгия.

Из архивных источников явствует, что первые представители линейного казачества Кубани стали выдвигаться на высокую награду еще с 1810 г [22, л. 951], и понятно, что за последующие более чем полувековые боевые действия счет награжденных исчислялся уже многими сотнями. Нельзя не отметить и то, что тогда, в пылу экспедиций и сражений эпохи, никто и не пытался систематизировать сведения о кавалерах, устанавливать их имена, отчества и фрамилии, станичную принадлежность, номера наград и описывать сами совершенные подвиги. В лаконичной заметке, опубликованной на страницах «Кубанских войсковых ведомостей» за 1869 г., невольно подтверждалась эта далеко не оптимистичная тенденция, сложившаяся за предыдущие десятилетия, хотя в ней же приводились и, по всей видимости, первые обобщенные статистические выкладки, касавшиеся героев-кубанцев.

«По случаю минувшего столетнего праздника ордена Св. Георгия, в войсковом штабе были собраны для представления по требованию в Главный штаб, сведения, между прочим и о числе чинов в Кубанском войске, имеющих знаки отличия военного ордена. Оказывается, что после смерти в последнее время нескольких престарелых кавалеров первой степени, таковых, т.е. имеющих все четыре степени, во всем войске осталось лишь двое: 2-й бригады урядник Мартын Братухин, и 1-й бригады казак Иван Чернышев, оба отставные. Знаки, четвертой, третьей и второй степени т.е. золотой крест без банта имеется у 36 чинов офицеров, урядников и казаков; двух степеней (четвертой и третьей) имеются у 203 чинов а одной четвертой степени у 4433 человек. Таким образом в настоящее время в войске, кроме Собственного Его Величества конвоя и артиллерии, состоит всего кавалеров военного ордена, офицеров и нижних чинов, отставных и служащих 4674 из прилагаемой ведомости видно распределение всех их между частями войска» [19]

Таблица 1

Сведения о числе кавалеров военного ордена Кубанского Казачьего войска

\begin{tabular}{|c|c|c|c|c|c|c|c|c|}
\hline \multirow{3}{*}{ Части } & \multicolumn{4}{|c|}{ Офицеров служащих и отставных } & \multicolumn{4}{|c|}{ Нижних чинов } \\
\hline & \multicolumn{4}{|c|}{ Степени ордена } & \multicolumn{4}{|c|}{ Степени ордена } \\
\hline & I $\mathbf{c T}$. & II $\mathbf{~ c t . ~}$ & III ст. & IV ст. & I ст. & ІІ ст. & III ст. & IV ст. \\
\hline $\begin{array}{l}\text { Округов: } \\
\text { Таманского } \\
\text { Екатеринодарского } \\
\text { Ейского }\end{array}$ & & $\begin{array}{l}2 \\
3 \\
1\end{array}$ & $\begin{array}{l}8 \\
6 \\
4\end{array}$ & $\begin{array}{l}66 \\
93 \\
39\end{array}$ & & $\begin{array}{l}2 \\
3 \\
1\end{array}$ & $\begin{array}{c}21 \\
11 \\
8\end{array}$ & $\begin{array}{l}463 \\
405 \\
576\end{array}$ \\
\hline $\begin{array}{l}\text { Бригад: } \\
1 \text {-й (Кавказской) } \\
\text { 2-й (Кубанской) } \\
\text { 3-й (Ставропольской) } \\
\text { 4-й (Хоперской) } \\
\text { 5-й (Урупской) } \\
\text { 6-й (Лабинской) }\end{array}$ & & 1 & $\begin{array}{l}2 \\
6 \\
5 \\
5 \\
\\
1\end{array}$ & $\begin{array}{l}22 \\
42 \\
41 \\
27 \\
20 \\
21\end{array}$ & $\begin{array}{l}1 \\
1\end{array}$ & $\begin{array}{l}3 \\
3 \\
2\end{array}$ & $\begin{array}{c}29 \\
13 \\
13 \\
8 \\
6 \\
19\end{array}$ & $\begin{array}{l}439 \\
409 \\
394 \\
295 \\
151 \\
373\end{array}$ \\
\hline $\begin{array}{l}\text { Отдельных полков: } \\
\text { 22-го } \\
23-\text {-го } \\
\text { 24-го } \\
\text { 25-го } \\
\text { Адагумского } \\
\text { Абинского } \\
\text { Псекупского }\end{array}$ & & $\begin{array}{l}2 \\
1 \\
2\end{array}$ & $\begin{array}{l}3 \\
4 \\
3 \\
1 \\
\\
2 \\
1\end{array}$ & $\begin{array}{c}4 \\
12 \\
7 \\
5 \\
7 \\
7 \\
6\end{array}$ & & $\begin{array}{l}2 \\
1 \\
1\end{array}$ & $\begin{array}{l}5 \\
7 \\
2 \\
1 \\
3 \\
3 \\
1\end{array}$ & $\begin{array}{c}93 \\
107 \\
51 \\
32 \\
70 \\
90 \\
49\end{array}$ \\
\hline $\begin{array}{l}\text { Шапсугского } \\
\text { берегового } \\
\text { Пешего батальона }\end{array}$ & & & & 5 & & & & 12 \\
\hline Всего & & 13 & 51 & 424 & 2 & 23 & 152 & 4009 \\
\hline
\end{tabular}


Мысль, сформулированная в газетной заметке о том, что уже в 1869 г. в Кубанском войске насчитывался уже далеко неполный перечень героев Кавказской войны и прочих имперских кампаний, без труда находит подтверждение в архивных документах. Так, еще до завершения покорения Западного Кавказа, в 1861 г. умер урядник 1-го Кавказского полка Макар Афанасьевич Орехов, обладавший тремя престижными наградами (знаком отличия военного ордена (ЗОВО) Св. Георгия 4 ст. № 2906,3 ст. № 764 и 2 ст. № 316) [29, л. 115] и являвшийся, по всей видимости, самым выдающимся участником сражений с горцами в своей родной ст. Новодонецкой $[13$, л. 310].

В предлагаемой статье хотелось бы обратить более пристальное внимание на тех представителей линейного казачества Кубани, которые заслужили полный бант георгиевских крестов в давно ушедшую эпоху покорения Северного Кавказа. Как вытекает из обнаруженного в фондах военно-исторического архива (РГВИА) послужного списка, упомянутого в газетной заметке урядника Мартына Леонтьевича Братухина, сам герой Кавказской войны происходил из ст. Прочноокопской. Это старейшее линейное поселение было основано в июле 1794 г. выходцами из Пятиизбянской, Есауловской, Глазуновской, Сиротинской, Заполянской и Малодельской станиц Войска Донского $[23$, л. 235-235 об.]. С момента своего появления на кубанском правобережье Прочноокопская оплот старообрядчества в регионе, жители которой категорически отвергали попытки официальных церковных властей как-то учитывать своих прихожан с помощью метрических книг и исповедных росписей [1, л. 1-10]. Именно поэтому в формуляре М. Л. Братухина нет даты рождения, и в связи с этим можно опираться только на один из известных списков прочноокопских раскольников, датируемый 9 декабря 1834 г. и составленный исключительно по приказу полкового командира. Согласно сохранившегося документа, Мартын Братухин родился около 1824 г. и там же, в Прочноокопской, появился на свет его отец Леонтий Васильевич (около 1796 г.) [1, л. 93]. Другой список, отложившийся в фондах Астраханского госархива, а именно «Ведомость о находящихся в Прочноокопской, Усть-Лабинской, Кавказской, Григориполисской и Темнолесской станицах старообрядцах поповской секты, именуемой порознь в мужеском и женском поле душах» за 1805 г., позволяет более подробно ознакомиться с интересующей нас казачьей семьей.

В нем указано, что в ст. Прочноокопской в то время проживали: вдовец Дмитрий Братухин 51-го года с сыновьями Василием - 30-ти лет, Филиппом - 29-ти лет, Захаром - 15-ти лет, Леоном 6-ти лет, Савелием - 1-го года и дочерью Ефимией - 14-ти лет. У Василия Дмитриевича, в свою очередь, была своя семья: жена Пелагея - 29-ти лет, дочери: Матрена - 13-ти, близнецы Аграфена и Матрена 2-я по 12 лет, Анисья - 3-х лет и, наконец, сын Леон (Леонтий) - 8-ми лет, отец будущего героя [1, л. 18об.]. Судя по всему, ста- рейший представитель рода Дмитрий Братухин, происходил из донской станицы Пятиизбянской и по всей видимости, именно его родственники, отставные казаки из этой станицы Наум, Павел и Петр Братухины участвовали в волнениях на Дону 1793-1794 гг. «...были в дерзости и жесточайше наказаны», после чего их определили в число переселявшихся на Кавказскую линию [33, c. 228].

Из послужного списка, составленного 29 января 1887 г., явствует, что Мартын Братухин имел вероисповедание старообрядческое, владел грамотой, но мастерства никакого не знал [24, л. 1 -6об.]. 1 января 1845 г. присягал на верность службе с последующим зачислением в Кубанский конный полк Кавказского линейного казачьего войска. Подобно большинству линейцев той эпохи он неоднократно привлекался к кордонной службе, однако не менее часто участвовал в военных экспедициях, направлявшихся в разные районы Закубанья. Согласно формуляра, в январе 1845 г он находился при разбитии аула за р. Белой, в 1846 г. брал неприятельские коши за р. Лабой, в 1848 г. - вновь на р. Белой, а в 1849 г. - в верховьях Урупа, Кяфара и Зеленчуков при «... поражении скопищ горцев» и в сентябре этого же года опять за р. Белой.

В январе 1850 г. Мартын Леонтьевич производится в урядники 2-го Кубанского полка, а в ноябре этого же года за отличие при взятии Белореченского аула награждается знаком Св. Георгия за № 88626, хотя несколько ранее в январе ему довелось поучаствовать еще в походе на Малую Лабу против махошевцев. В 1851-1855 гг. урядник Братухин, как и в предыдущее время, сражается с закубанскими горцами, причем в одном из таких боев чудом избегает смерти. При захвате неприятельских кошей в 1855 г. под ним на полном карьере убивают лошадь, а сам Братухин повреждает обе ноги (собственным кинжалом он случайно еще и накалывает ногу выше колена) и получает травму головы. Оправившись от полученных ран, бравый урядник в следующем 1856 г вновь оказывается в Закубанье, где принимает участие в закладке Шедокского (на одноименной реке) и Псебайского (на Малой Лабе) укреплений. За отличие в перестрелках с горцами при Шедоке, в марте 1856 г. Мартына Братухина представляют, минуя третью степень награды (вместо нее ему выплачивают вторую треть добавочного жалования) $[24$, л. 26 об.] сразу к ЗОВО Св. Георгия 2-й степени с № 229 [30].

Вскоре отважный линеец становится и полным георгиевским кавалером, поскольку 15 апреля 1857 г. за особое отличие ему вручают ЗОВО 1-й степени с № 108. Согласно послужного списка, высокую награду Братухин снискал «...при занятии крепости Майкопа в жаркой перестрелке с горцами...» $[24$, л. 1 - 6 об.]. В 1858 г. заслуженный урядник продолжает находится на фронтирах Западного Кавказа, но вскоре 1 января 1860 г Мартын Леонтьевич завершает свою воинскую карьеру, наполненную походами и трудами, и за 
выслугой лет перечисляется в отставку. Помимо указанных георгиевских знаков отличия трех степеней, урядник Братухин также был удостоен медалей: бронзовой на Андреевской ленте «В память войны 1853 и 1856 годов» и серебряной «За покорение Западного Кавказа». Кроме того, в ноябре 1850 г. в проезд Его Высочества Александра Николаевича (будущего императора Александра II) и за отличие против горцев его поощрили 11 рублями серебром [24, л. $1-6$ об.].

Выйдя в отставку, М.Л. Братухин, судя по сохранившимся разрозненным свидетельствам представлял родную ст. Прочноокопскую по разным торжественным случаям. Так, 21 сентября 1888 г. во время посещения г. Екатеринодара императором Александром III с семьей, отставной урядник Братухин являлся знаменосцем почетного караула, составленного из ветеранов Кубанского войска, причем его ассистентами выступили одностаничники, урядники Петр Кочергин (имел георгиевские кресты 4-й, 3-й и 2-й степени) и Петр Казанков (обладал полным Георгиевским бантом), удостоенные высоких наград за отличие в Кавказской и русско-турецкой войне 1877-1878 гг $[17$, c. 19,83$]$

Известно, что в следующем 1889 г. отставного урядника ст. Прочноокопской Мартына Братухина за заслуги на общественном поприще поощрили серебряной медалью с надписью: «За усердие» [21]. Будучи стойким приверженцем старообрядчества и фигурой достаточно публичной, Мартын Леонтьевич тогда же, в конце 80-х гг. XIX в., выступал ходатаем за разные нужды прочноокопской общины [18, с. 306]. К сожалению, фрагментарность данных и отсутствие метрических книг по ст. Прочноокопской интересующего периода, не позволяют пока выяснить, когда окончил свой земной путь один из видных героев Кавказской войны.

В отличии от биографиии М. Л. Братухина, реконструкция жизненного пути другого заметного участника покорения Кавказа, упомянутого в газетной заметке 1869 г. - Ивана Чернышева представляется куда более сложной по причине отсутствия самого послужного списка. Удалось установить, что он родился около 1818 г. в ст. Казанской Кавказского линейного полка в семье казака Якова Михайловича Чернышева и его супруги Ефимии Петровны [2, л. 267, 663об.] Чернышевы относились к казанским первопоселенцам, происходили из однодворцев Украинской линии и до того, как перебраться на Кавказ, проживали в слободе Новоайдарской Донецкого уезда Екатеринославского наместничества (сегодня - г. Новоайдар, центр одноименного района Луганской области Украины). Дед Михаил Акимович служил казаком, а прадед Аким Тросимович имел чин подпрапорщика Екатеринославского или иначе - Новодонского казачьего войска [5, л. 1114 - 114об.], отличившегося в русско-турецкой войне 1787-1791 гг.

По всей видимости, в конце 30-х гг. ХІХ в. Иван Яковлевич Чернышев был призван в ряды Кав- казского линейного полка (с 1846 г. - 2-го Кавказского полка КЛКВ), где начались его боевые будни, наполненные кордонной службой и походами против горцев. Известно, что первую георгиевскую награду под № 84269 приказный Чернышев снискал в 1848 г. за отличие против закубанцев в верховьях реки Гиаги [6, л.97], однако в источниках за последующие годы факты о новых награждениях описываемого представителя ст. Казанской не обнаруживаются. Более того, в архивном деле из фонда 496 «Капитул российских орденов Министерства Императорского двора» государственного исторического архива (РГИА), обнаруживается запись, что казак Иван Чернышев, обладавший знаком отличия за № 84269 , умер в 1870 г., и сама награда, согласно действовавшего правила, была возвращена в Орденский Капитул 12 октября 1870 г. за № 1827 [31, л. 52]. Таким образом, автор газетной заметки ошибочно отнес Ивана Чернышева к числу полных георгиевских кавалеров, воспользовавшись непроверенной информацией, предоставленной, вероятно, бригадным писарем, не ставшим вникать в суть вопроса.

Выявленное досадное недоразумение, вместе с тем, вовсе не свидетельствует о невозможности установления прочих выдающихся представителей линейного казачества Кубани, героически проявивших себя в многолетней борьбе с горцами. В том же фонде 496 РГИА удалось обнаружить урядника 2-го Кубанского полка Ивана Сесекина, обладавшего званием полного георгиевского кавалера за период Кавказской войны, правда, фактически располагавшего только 4-й и 1-й степенями, поскольку за 3-ю и 2-ю степени знака отличия он получал добавочное жалование $[30$, л. 26об.]. Привлечение различных архивных источников позволяет заключить, что вышеназванный герой являлся не только сослуживцем описанного урядника М. Л. Братухина, но и его одностаничником. Можно в этой связи утверждать, что пафос одного из современников, отмечавшего в 1868 г., что 1-я прочноокопская сотня Кубанского полка «...пользовалась особенно громкою славою среди всей кавказской кавалерии...) [20], во многом подтверждается фактами награждения местных казаков престижными наградами эпохи. Нельзя в этой связи не упомянуть и о том, что за период Кавказской войны (с учетом кампаний против венгров, турок и поляков 1849, 1853-1856 и 1863-1864 гг.) не менее сотни местных уроженцев представлялись к знаку отличия военного ордена Св. Георгия. Сама ст. Прочноокопская, где c начала XIX в. располагался полковой, а затем и бригадный штабы, достаточно быстро обрела статус «офицерской» станицы, а около трех десятков ее казаков влились в командные ряды Кавказского линейного и позднее (с 1861 г.) - Кубанского войска.

Возвращаясь к интересующей нас фигуре, отметим, что, как и М. Л. Братухин, урядник Иван Матвеевич Сесекин (в источниках встречается и такая форма написания фамилии как Сесёкин, 
видимо, подчеркивающая станичную манеру произнесения) принадлежал к старообрядческой общине, главенствовавшей в Прочноокопской, что создает трудности в реконструкции его биографии. Исходя из документальных сведений, обнаруженных в различных архивохранилищах, датой его рождения могут выступать 1830, 1832, 1833 и даже 1834 гг. [14, л. 97; 25, л. 19]. Старейшим представителем рода выступает Михаил Сесекин (Сесёкин), родившийся около 1764 г. на Дону в ст. Пятиизбянской, который, по сведениям за сентябрь 1839 г., являлся отставным урядником и, несмотря на преклонный возраст, управлял хозяйством и владел лавкой в ст. Прочноокопской [25, лл. 19, 98]. Ранее в 1818 г. он, зная грамоту, выступал ходатаем от раскольничьих общин Прочноокопской, Кавказской и Усть-Лабинской станиц, просивших о назначении к ним собственного священника, отправлявшего требы по старому обряду [15, л. 3-8]. Сын Михаила Тихон (родился около 1790 г.) поступил в Кубанский полк в 1806 г и после двух с лишним десятков лет линейной службы сумел отличиться в ходе русско-турецкой войны 1828-1829 гг., по итогам которой удостоился производства в хорунжие. За эту же кампанию Тихона Сесекина представили к $30 \mathrm{BO}$ Св. Георгия (номер знака, к сожалению, не указан в двух формулярах), а позднее удостоился и ордена Св. Анны за 20-тилетнюю беспорочную службу с № 170420, выйдя в отставку в чине сотника, по всей вероятности, в середине 40-х гг. XIX в. [26, л. 79об., л. 171об. - 175].

Сыновья Тихона Сесекина Матвей (родился около 1808 г.) и Иван (родился около 1812 г.), как и полагалось линейным казакам, также пошли по военной стезе, - причем, старший сын намного превзошел своего родителя. По данным формуляра, Матвей Тихонович Сесекин вступил в службу казаком в Кубанский полк в 1831 г. Спустя пять лет за отличие в делах против горцев удостоился $30 \mathrm{BO} \mathrm{C}_{\mathrm{B}}$. Георгия с № 71190, а уже в 1839 г., также за отличие в сражениях, его произвели в хорунжие [27, лл. 219об. - 220]. За 20 с лишним лет походов и сражений, наполненных всевозможными лишениями и трудностями, Матвей Сесекин достиг штаб-офицерского чина войскового старшины, но в 1853 г. вышел в отставку с характерной фрормулировкой: «за ранами» [16, л. 36]. Его младший брат Иван Тихонович Сесекин дослужился только до урядника, но и он в 1843 г. также был поощрен георгиевской наградой №77900 за проявленное мужество в делах против горцев [8, л. 740б., 325об.].

Таким образом, примеры героического служения Отечеству будущему полному георгиевскому кавалеру Ивану Матвеевичу Сесекину уже c самых ранних пор подавали его ближайшие родственники. К сожалению, полного послужного списка этого выдающегося представителя ст. Прочноокопской на текущий момент обнаружить не удалось, но зато в анналах РГВИА отыскался его краткий формуляр за 1860 г. Судя по записи в документе и принадлежности к офицерской се- мье (где сыновей могли определять на службу уже в 14-16 лет), Иван Сесекин зачислился во 2-й Кубанский полк Кавказского линейного казачьего войска (КЛКВ) с 1 января 1848 г. Походы в Закубанье этого же года завершились для Сесекина получением престижной воинской награды с номером 84683 [28, л. 165об. - 169], а вскоре, по итогам очередных экспедиций в земли черкесов 1 сентября 1851 г., последовало и производство юного Сесекина в урядники.

Дальнейшие записи формуляра информируют, что в период 1852-1857 гг. урядник Иван Ceceкин ежегодно участвовал в закубанских походах и в одном из них вновь заметно отличился [28, л. 165об. - 169]. Согласно сведений из фонда Капитула, 3ОВО Св. Георгия 1-ой степени с № 107 отважный урядник получил «...за отличия, оказанные в делах и перестрелках с горцами в течение 1855 и 1856 гг. на правом крыле Кавказской линии и на Черноморской кордонной линии, а равно за труды, понесенные во время устройства Мало-Лабинской линии» [30, л. 26об.]. Привлечение вышеупомянутого краткого послужного списка из фондов РГВИА позволяет утверждать что Иван Сесекин смог продолжить традиции своего офицерского рода, и 11 ноября 1858 г. его произвели в хорунжие [28, л. 165oб. - 169; 10 , л. 2]. Обретение офицерских погон и заслуги ближайших родственников могли бы помочь Ивану Матвеевичу в поиске куда более спокойной должности во 2-м Кубанском полку или на тот момент 4-ой бригаде Кавказского линейного войска. Но сам описываемый представитель ст. Прочноокопской, вероятно, не мыслил себя вне фронтовой службы, и строки документа лишний раз подтверждают свойства характера боевого офицера. Как гласит последняя запись формуляра, с 1 декабря 1859 г. по 31 января 1860 г. хорунжий Сесекин находился в действиях Псефирского отряда на реках Псефир и Серале для прикрытия Лабинской линии и обозрения предгорий между реками Уль, Кубань и Большой Лабой. Сопоставление других архивных данных дает основание утверждать, что молодой офицер неоднократно проявил себя на завершающем этапе покорения Западного Кавказа, поскольку до 1864 гг. Ивана Матвеевича производят в сотники 13-го конного (бывшего 2-го Кубанского) полка 2-й бригады теперь уже Кубанского войска [10, л. 1].

Нельзя не отметить и то, что в завершающих схватках с абадзехами, шапсугами и убыхами серебряные погоны хорунжего в 1864 г. заслуживает и младший брат Ивана - Василий Матвеевич Сесекин [9, л. 1153]. Что касается самого описываемого героя, то по всей видимости, частые спутники казачьего офицера-линейца - раны, лишения и невзгоды - сделали свое пагубное дело. В посемейном списке ст. Прочноокопской, составленном в апреле 1864 г., служащий сотник Иван Матвеевич Сесекин (имевший от роду всего 30 с небольшим лет) уже значится умершим, а в семье его отца, отставного войскового старшины М. Т. Сесекина, продолжали проживать вдова 
сотника Марья Михайловна - 30-ти лет (она являлась дочерью урядника Михаила Артемовича Зотова из соседней ст. Григориполисской, также исповедовавшего старообрядчество) и её сын Яков - 7-ми лет [10, л. 1об.]. Смерть молодого обер-офицера косвенно подтверждает и общий список сотников Кубанского войска, составленный в конце 1864 г. [12, л. 1162-1304].

Обнаруженная информация о двух выдающих ся представителях линейного казачества Кубани ставших в годы Кавказской войны полными георгиевскими кавалерами, едва ли может считаться исчерпывающей. Десятки пустых страниц вышеупомянутого фонда 496 РГИА, в которых проставлены только номера знаков без какого-либо указания сведений о самих награжденных [30], недвусмысленно свидетельствует о том, что имена многих героев все еще остаются в небытие.

\section{Источники и литература}

1. Государственный архив Астраханской области (далее - ГААО). Ф.599. ОП. 2. Д. 6020

2. ГААО. Ф. 599. ОП. 2. Д. 1595.

3. ГААО. Ф. 599. ОП. 2. 3283

4. ГААО. Ф. 599. Оп. 2. Д. 7148

5. Государственный архив Воронежской области. Ф.И-18. ОП.1. Д.152

6. Государственный архив Краснодарского края (далее - ГАКК). Ф. 670. Оп. 1. Д. 37.

7. ГАКК. Ф. 358. ОП. 1. Д. 16.

8. ГАКК. Ф. 396. ОП. 1. Д. 1025.

9. ГАКК. Ф. 396. ОП. 2. Д. 221.

10. ГАКК. Ф. 358. ОП. 1. Д. 44

11. ГАКК. Ф. 396. ОП. 2. Д. 221

12. ГАКК. Ф. 396. Оп. 2. Д. 220.

13. Государственный архив Ставропольского края (далее - ГАСК). Ф. 135. Оп. З. Д. 1033.

14. ГАСК. Ф. 79. ОП. 1. Д. 1539.

15. ГАСК. Ф. 435. ОП. 1. Д. 244.

16. ГАСК. Ф. 1300 . ОП. 1. Д. 439.

17. Дмитренко И. И. Пребывание их Императорских Величеств Государя Императора Александра Александровича и Государыни Императрицы Марии Федоровны с августейшими детьми, наследником цесаревичем Николаем Александровичем и Великим Князем Георгием Александровичем, в Кубанском казачьем войске в сентябре месяце 1888 года. СПб.: Типография штаба отдельного корпуса жандармов, 1898. 94 с.

18. Зудин А. И. Старообрядческое духовенство Белокриницкой иерархии в Кубанской области. Вторая половина XIX - начало XX вв. / Кубанский сборник. T. IV (25); под ред. О. В. Матвеева, Г. В. Кокунько. Краснодар: «Книга», 2012. $488 \mathrm{c}$.

19. Кубанские войсковые ведомости. 1869. №48

20. Кубанские войсковые ведомости. 1868. №19.

21. Кубанские областные ведомости. 1889. №19.

22. Российский государственный военно-исторический архив (далее - РГВИА. г. Москва). Ф. 13454. Оп. 1. Д. 422.

23. РГВИА. Ф. 41. Оп. 1/199. Д. 203.

24. РГВИА. Ф. 643. ОП. 1. Д. 3.

25. РГВИА. Ф. 15044. Оп. 1. Д. 25. Ч. 1

26. РГВИА. Ф. 14719 . ОП. 7. Д. 80

27. РГВИА. Ф. 14719. ОП. 7. Д. 52

28. РГВИА. Ф. 330 . ОП. 55. Д. 980

29. Российский государственный исторический архив (далее - РГИА. г. Санкт-Петербург). Ф. 496. Оп. 3. Д. 799

30. РГИА. Ф. 496. Оп. 3. Д. 765. (Список по знакам отличия Военного ордена 1 степени, с № 1-2000).

31. РГИА. Ф. 496. Оп. 3. Д. 755

32. Сводные списки кавалеров Георгиевского креста 1914-1922 гг. / в 14-ти т. / сост. С. Б. Патрикеев. М.: Духовная Нива, 2012-2015.

33. Служба донских казаков. Мятеж на Дону: материалы по истории и генеалогии казачества / авт.-сост. В. А. Гусев. Вып. 11. Волгоград: «Панорама», 2018. 392 с.

34. Страницы казачьей славы: Об участии казаков Кавказского отдела Кубанского казачьего войска в Первой мировой войне 1914-1917 гг. В 2-х т. / сост. М. С. Тимченко, К. В. Шкуро. Краснодар: «Фамилия», 2014. 688 с.

35. Стрелянов (Калабухов) П. Н. Казаки Кубанского Войска в Великой, гражданской войнах и эмиграции. Чины конных полков, пластунских батальонов, артиллерийских батарей, особых сотен, военно-учебных заведений и войсковых структур. В 2-х т. М.: Стихира, 2017. Т. 1. А-Л. 876 с. Т. 2. К-Я. 848 с.

\section{References}

1. State archive of Astrakhan territory (GAAO). F. 599. Inv. 2. D. 6020. (In Russian)

2. GAAO. F. 599. Inv. 2. D. 1595. (In Russian)

3. GAAO. F. 599. Inv. 2. D. 3283. (In Russian)

4. GAAO. F. 599. Inv. 2. D. 7148. (In Russian)

5. State archive of Voronezh territory. F.I-18. Inv. 1. D. 152. (In Russian)

6. State archive of Krasnodar territory (GAKK). F. 670. Inv. 1. D. 37. (In Russian) 
7. GAKK. F. 358. Inv. 1. D. 16. (In Russian)

8. GAKK. F. 396. Inv. 1. D. 1025. (In Russian)

9. GAKK. F. 396. Inv. 2. D. 221. (In Russian)

10. GAKK. F. 358. Inv. 1. D. 44. (In Russian)

11. GAKK. F. 396. Inv. 2. D. 221. (In Russian)

12. GAKK. F. 396. Inv. 2. D. 220. (In Russian)

13. State archive of Stavropol territory (GASK). F. 135. Inv. 3. D. 1033. (In Russian)

14. GASK. F. 79. Inv. 1. D. 1539. (In Russian)

15. GASK. F. 435. Inv. 1. D. 244. (In Russian)

16. GASK. F. 1300. Inv. 1. D. 439. (In Russian)

17. Dmitrenko I. I. Prebyvanie ih Imperatorskih Velichestv Gosudarya Imperatora Aleksandra Aleksandrovicha i Gosudaryni Imperatricy Marii Fedorovny s avgustejshimi det'mi, naslednikom cesarevichem Nikolaem Aleksandrovichem i Velikim Knyazem Georgiem Aleksandrovichem, v Kubanskom kazach'em vojske v sentyabre mesyace 1888 goda (Stay of their Imperial Majesties Emperor Alexander Alexandrovich and Empress Maria Feodorovna with August children, heir Tsarevich Nikolai Alexandrovich and Grand Duke George Alexandrovich, in the Kuban Cossack army in September 1888). St. Petersburg: Printing house of the headquarters of a separate corps of gendarmes, 1898. 94 p. (In Russian)

18. Zudin A. I. Staroobryadcheskoe duhovenstvo Belokrinickoj ierarhii v Kubanskoj oblasti. Vtoraya polovina XIX - nachalo $X X v v$. (Old believers clergy Belokrinitskoy hierarchy in the Kuban region. The second half of XIX-the beginning of XX centuries) // Kubanskij sbornik. Vol. IV (25); ed by O. V. Matveev, G. V. Kokun'ko. Krasnodar: Kniga publ., 2012. 488 p. (In Russian)

19. Kubanskie vojskovye vedomosti. 1869. No. 48. (In Russian)

20. Kubanskie vojskovye vedomosti. 1868. No. 19. (In Russian)

21. Kubanskie oblastnye vedomosti. 1889. No. 19. (In Russian)

22. Russiam state military amdhistorical archive (RGVIA). F. 13454. Inv. 1. D. 422. (In Russian)

23. RGVIA. F. 41. Inv. 1/199. D. 203. (In Russian)

24. RGVIA. F. 643. Inv.1. D. 3. (In Russian)

25. RGVIA. F. 15044. Inv.1. D. 25. Part. 1. (In Russian)

26. RGVIA. F. 14719. Inv.7. D. 80. (In Russian)

27. RGVIA. F. 14719. Inv.7. D. 52. (In Russian)

28. RGVIA. F. 330. Inv. 55. D. 980. (In Russian)

29. Russian state historical archive (RGIA). F. 496. Inv. 3. D. 799. (In Russian)

30. RGIA. F. 496. Inv. 3. D. 765. (In Russian)

31. RGIA. F. 496. Inv. 3. D. 755. (In Russian)

32. Svodnye spiski kavalerov Georgievskogo kresta 1914-1922 gg. (Consolidated lists of cavaliers of the St. George cross 1914-1922) / In 14 Vols. / compiler S.B. Patrikeev. Moscow: Duhovnaya Niva publ., 2012-2015. (In Russian)

33. Sluzhba donskih kazakov. Myatezh na Donu: materialy po istorii i genealogii kazachestva (Service of the Don Cossacks. Rebellion on the Don: materials on the history and genealogy of the Cossacks) / compiler V. A. Gusev. Issue. 11. Volgograd: Panorama publ., 2018. 392 p. (In Russian)

34. Stranicy kazach'ej slavy: Ob uchastii kazakov Kavkazskogo otdela Kubanskogo kazach'ego vojska v Pervoj mirovoj vojne 1914-1917 gg. (See, for example: Pages of Cossack glory: On participation of Cossacks of the Caucasian Territory of the Kuban Cossack army in the First World War 1914-1917). In 2 Vols / compiler M.S. Timchenko, K.V. SHkuro. Krasnodar: Familiya publ., 2014. 688 p. (In Russian)

35. Strelyanov (Kalabuhov) P. N. Kazaki Kubanskogo Vojska v Velikoj, grazhdanskoj vojnah i emigracii. CHiny konnyh polkov, plastunskih batal'onov, artillerijskih batarej, osobyh soten, voenno-uchebnyh zavedenij i vojskovyh struktur (The Cossacks of Kuban army in the Great, Civil wars and emigration. Ranks of cavalry regiments, infantry battalions, artillery batteries, special cavalry squads, military educational institutions and military structures). In 2 Vols. Moscow: Stihira publ., 2017. Vol. 1. A-L. 876 p. Vol. 2. K-YA. 848 p. (In Russian)

\section{Сведения об авторе}

Колесников Владимир Александрович - кандидат исторических наук, доцент кафедры гуманитарных дисциплин Ставропольского краевого института развития образования, повышения квалификации и переподготовки работников образования (Ставрополь) / kolesnikov-va@yandex.ru

\section{Information about the author}

Kolesnikov Vladimir - PhD in Historical Sciences, Associate Professor, Chair of Humanities, Stavropol regional Institute of education development, advanced training and retraining of education workers (Stavropol) / kolesnikov-va@yandex.ru 